Research Article

\title{
Matrine Attenuates D-Galactose-Induced Aging-Related Behavior in Mice via Inhibition of Cellular Senescence and Oxidative Stress
}

\author{
Kaiyue Sun (D), Pengyu Yang, Rong Zhao, Yuting Bai, and Zijiao Guo \\ College of Animal Science and Veterinary Medicine, Shanxi Agricultural University, Taigu 030801 Shanxi, China \\ Correspondence should be addressed to Kaiyue Sun; sunkaiyue21@163.com
}

Received 20 June 2018; Revised 15 September 2018; Accepted 15 October 2018; Published 27 November 2018

Academic Editor: Valentina Pallottini

Copyright (C) 2018 Kaiyue Sun et al. This is an open access article distributed under the Creative Commons Attribution License, which permits unrestricted use, distribution, and reproduction in any medium, provided the original work is properly cited.

\begin{abstract}
The present study was designed to evaluate the effects of matrine (MAT) on D-galactose- (D-gal-) induced aging and relative mechanism. Vitamin E at the dose of $100 \mathrm{mg} / \mathrm{kg}$ was used as a standard positive control. MAT significantly improved the D-galinduced recognition and spatial memory impairment in novel object recognition and Y maze tests, and exercise endurance decreased in the weight-loaded swimming test at 2 and $10 \mathrm{mg} / \mathrm{kg}$. We found that D-gal treatment induced noticeably agingrelated changes such as reducing thymus coefficients, increasing the pathological injury and cellular senescence of liver, spleen, and hippocampus, as well as an increase in cyclin-dependent kinase inhibitor $p 16, p 19$, and $p 21$ gene expression and the interleukin- $1 \beta$ expression in the liver and hippocampus. MAT showed effective protection on such changes. Furthermore, MAT decreased the oxidative stress of the liver, plasma, and brain, as evidenced by increased total antioxidant capacity, total superoxide dismutase, and catalase activities and decreased the malondialdehyde level. Additionally, there was a significant positive correlation between swimming time in weight-loaded swimming time and thymus index. MAT ameliorated agingrelated disorder caused by D-gal through the inhibition of both cellular senescence and oxidative stress. The study provides further evidence for drug development of MAT for prevention or treatment of the aging-associated disorder.
\end{abstract}

\section{Introduction}

As the population increases and lifespan is extended, the aging population becomes large and aging-related diseases have brought great attention worldwide. Aging is a biological process featured as a progressive degeneration of physiological functions which results in an increase in morbidity and death rate. Aging is one of the major factors of brain decline involved in gradual learning and memory loss, cognitive disorders, and dementia, like Alzheimer's disease [1,2]. Moreover, fatigue is easily felt in both men and women as aging; the fatigue prevalence reached its highest level when the individuals reached the age of 90 years for both men and women [3]. Fatigue is associated with immune disorder and dysfunction of the antioxidant defense system, and so on $[4,5]$. Harman proposed the free radical theory in 1956, and since then, numerous studies have proved that reactive oxygen species (ROS) play an essential role in aging [6-8]. High levels of
ROS could induce oxidative stress and destroy the structure of DNA, phospholipids, and proteins, finally resulting in cellular and tissue injury [9]. This is a critical mechanism for ROS-induced aging. Meanwhile, mammalian cells have an antioxidant system able to scavenge high levels of ROS. Total superoxide dismutase (T-SOD), catalase (CAT), and vitamin $\mathrm{E}(\mathrm{VE})$ are the critical members of this antioxidant system [10].

The previous study has shown that chronic exposure to D-galactose (D-gal) caused similar symptoms such as natural aging [11]. Overload of D-gal could accelerate the production of ROS and lead to oxidative stress [12]. Brain and liver dysfunction is closely relative to aging, and it is susceptible to Dgal caused by oxidative injury [13-15]. Furthermore, it has shown that the number of senescent cells and apoptosis in the liver and brain increased in D-gal-induced aging mice $[16,17]$. Recent studies have shown that senescent cells accumulated in various aging and diseased tissues [18]. Cellular 
senescence is associated with age-related phenotypes causally, and the decrease in senescent cells can retard tissue dysfunction and extend healthspan [19]. Hence, a D-gal-induced aging model has been widely used for pharmacological studies of antiaging agents.

MAT, the major alkaloids extracted from traditional Chinese medicine Sophora flavescens, has numerous pharmacological activities, such as antitumor, antidiabetes, and cardioprotective effects [20-23]. MAT not only attenuates focal cerebral ischemic injury [24] but also protects against MTPT-induced Parkinson's disease via antioxidative stress [25]. However, whether MAT protects against aging induced by $\mathrm{D}$-gal and the underlying mechanisms have not been addressed yet. In the present study, we employed a Dgal-induced aging mouse model to investigate the protective effect of MAT. We found that D-gal treatment induced noticeably aging-related changes, including cognitive impairment and memory deficits; decrease in swimming time in the weight-loaded swimming test and thymus coefficient; increase in senescence-associated $\beta$-galactosidase (SA- $\beta$ gal) activity; $p 16, p 19, p 21$, interleukin- (IL-) $1 \beta$ and IL-6 gene expression; and oxidative stress in the liver, spleen, and brain. MAT's effect on memory deficit and endurance decline as well as the cellular senescence and oxidative stress levels were detected.

\section{Materials and Methods}

2.1. Animals and Drug Administration. Male ICR mice (8week-old, 30-35g) were purchased from Shanxi Medical University (Shanxi, China). Mice were housed 5 per cage, allowed to access food and water freely, and maintained in constant temperature $\left(23 \pm 1^{\circ} \mathrm{C}\right)$ and humidity $(55 \pm 5 \%)$ under a $12 \mathrm{~h}$ light/dark cycle (lights on $08: 00$ to $20: 00 \mathrm{~h}$ ). The investigation conformed to the International Guiding Principles for Biomedical Research Involving Animals (1985). The mice were used in each experiment to minimize both the number of animals used and their suffering. All experimental procedures were conducted and performed as the policies for animal care and use encompass regulations approved by the Institutional Animal Care and Use Committee of Shanxi Agricultural University.

The mice were randomly divided into five groups (9 mice in one group): control group (2\% ethanol in saline + saline), D-gal group ( $2 \%$ ethanol in saline $+150 \mathrm{mg} / \mathrm{kg} \mathrm{D}$ gal), VE group (VE $100 \mathrm{mg} / \mathrm{kg}+150 \mathrm{mg} / \mathrm{kg} \mathrm{D}$-gal), MAT low-dose group (MAT $2 \mathrm{mg} / \mathrm{kg}+150 \mathrm{mg} / \mathrm{kg} \mathrm{D}$-gal), and MAT high-dose group (MAT $10 \mathrm{mg} / \mathrm{kg}+150 \mathrm{mg} / \mathrm{kg} \mathrm{D}$-gal). The mice were treated with D-gal at a dose of $150 \mathrm{mg} / \mathrm{kg}$ for 6 weeks (s.c.). At the fifth week, the mice were given MAT or solvent ( $2 \%$ ethanol in saline, oral) for 4 weeks before the behavior test.

2.2. Drugs and Chemicals. MAT and VE were purchased from Aladdin Reagent Company (Shanghai, China); D-gal was purchased from Beijing Solarbio Science \& Technology Company (Beijing, China). All other materials were of the highest grade available.
2.3. Novel Object Recognition (NOR) Task. Learning and memory ability was detected by the NOR task as described previously [26]. The dimensions of the apparatus are $40 \mathrm{~cm} \times 25 \mathrm{~cm} \times 20 \mathrm{~cm}$ (length $\times$ width $\times$ height). Mice had been put into the apparatus for $5 \mathrm{~min}$ without objects for two days. The apparatus was cleaned using 70\% ethanol to eliminate the residual odor until dry. On the third day, the mice were tested by comparing two sessions: the training and test sessions. In the training session, the mice facing the wall were placed into the apparatus containing two identical objects and allowed to explore for $5 \mathrm{~min}$. The objects were placed in opposite adjacent corners, $5 \mathrm{~cm}$ away from the walls. The test session was performed $60 \mathrm{~min}$ after the training session, with one object instead of a novel one. Exploration was defined as the condition for which the mice directed the head or nose to the object no more than $1 \mathrm{~cm}$ or touched the object. However, if the mouse sited on the object, it was not considered as exploration. The discrimination ratio of each mouse is defined as $\mathrm{TN} /(\mathrm{TN}+\mathrm{TF})$ ratio ( $\mathrm{TF}=$ exploring time on the familiar object; $\mathrm{TN}=$ exploring time on the novel object).

2.4. Spontaneous Alternation Behavior Y-Maze Test. The Ymaze test was performed after NOR according to the previously described method [27]. The Y-maze contained three dark, polyvinyl plastic arms with $120^{\circ}$ angle between all arms, which were $30 \mathrm{~cm}$ long and $5 \mathrm{~cm}$ wide with $12 \mathrm{~cm}$ high walls. Mice were initially placed at the end of one arm and allowed to explore in the Y maze freely. The number of arm entries and the sequence of arm visits were recorded manually for each mouse for $8 \mathrm{~min}$. Then, the mouse was removed from the Y-maze to its house, and the Y-maze was cleaned with $70 \%$ ethanol to remove the odor until dry. The mouse consecutively entering into three different arms was defined as an actual alteration, i.e., BCA, $\mathrm{ABC}$, or $\mathrm{CAB}$, but not $\mathrm{ABB}$. Moreover, the percent of alteration was calculated as the number of actual alteration/total number of entering $\times 100$.

2.5. Weight-Loaded Swimming Test. The weight-loaded swimming test was performed as described previously [28]. Briefly, the dimensions of the tank are $30 \mathrm{~cm} \times 35 \mathrm{~cm} \times 60 \mathrm{~cm}$ (length $\times$ width $\times$ height) and filled with water $\left(23^{\circ} \mathrm{C} \pm 1^{\circ} \mathrm{C}\right)$. The mice were loaded aluminum ( $5 \%$ of their body weight) attached to the tail, and the fur of the mice was dripping wet with water. Then, the mice were placed into the tank individually. The time at which the animals were unable to bail out the water surface for 5 seconds was recorded.

2.6. Body Weight and Organ Coefficient Analysis. The mice were weighed every week. After the weight-loaded swimming test, the mice were sacrificed, and the weights of the organ were weighted by an accurate electronic balance. The tissue was stored at $-20^{\circ} \mathrm{C}$ until used for the biochemical studies. The organ coefficient was calculated using the following equation: organ index $(g / 100 g)=$ organ weight/body weight $\times 100$.

2.7. Morphological and Histological Analyses. The liver, spleen, and brain tissues were excised, fixed, and embedded in $4 \%$ paraformaldehyde. The sections $(5 \mu \mathrm{m})$ were stained 
TABLE 1: Forward and reverse primers for quantitative real-time PCR analysis.

\begin{tabular}{lcc}
\hline Primer & Forward & Reverse \\
\hline $18 S$ & $5^{\prime}$-TAA CCC GTT GAA CCC CAT T-3' & $5^{\prime}$-CCA TCC AAT CGG TAG TAG CG-3' \\
p16 & $5^{\prime}$-CTCAGCCCGCCTTTTTCTTC-3' & $5^{\prime}$-CGCCTTCGCTCAGTTTCTCATG-3' \\
$p 19$ & $5^{\prime}$-GTGGCTCTCGCTACTCTGTTG-3' & $5^{\prime}$-ATAGTGGATACCGGTGGACCT-3' \\
$p 21$ & $5^{\prime}$-ACTACCAGCTGTGGGGTGAG-3' & $5^{\prime}$-TCGGACATCACCAGGATTGG-3' \\
$I L-6$ & $5^{\prime}$-CCCCAATTTCCAATGCTCTCC-3' & $5^{\prime}$-CGCACTAGGTTTGCCGAGTA-3' \\
$I L-1 \beta$ & $5^{\prime}$-GCCACCTTTTGACAGTGATGAG-3' & $5^{\prime}$-GACAGCCCAGGTCAAAGGTT-3' \\
\hline
\end{tabular}

with haematoxylin and eosin (HE) (Beijing Solarbio Science \& Technology Company, Beijing, China). Briefly, the sections were deparaffinized with $100 \%$ xylene and rehydrated with gradient alcohol (100\% ethanol, $90 \%$ ethanol, $80 \%$ ethanol, and $70 \%$ ethanol) and distilled water. Then, the sections were washed in distilled water for three times and stained with haematoxylin for 10 minutes, differentiated in the differentiation liquid, and then washed with running tap water for $15 \mathrm{~min}$. The nucleus was counterstained with eosin for $1 \mathrm{~min}$ and dehydrated. The pathological changes were observed under an optical microscope (Olympus, Japan). The photograph was analyzed by ImageJ. The related nuclear size was compared to the control group; the percentage of the white pulp of the spleen = white pulp area/ total area.

2.8. Senescence-Associated $\beta$-Galactosidase (SA- $\beta$-Gal) Staining. The percentage of SA- $\beta$-gal-positive cells was determined using a senescence $\beta$-galactosidase staining kit (Beyotime Institute of Biotechnology, Haimen, China). Briefly, the sections $(10 \mu \mathrm{m})$ were washed with PBS three times and then incubated for 48 hours in SA- $\beta$-gal staining solution at $37^{\circ} \mathrm{C}$. Then, the samples were washed with PBS three times and coverslipped for direct imaging with a microscope (Olympus, Japan).

2.9. Biochemical Analysis. Before detection, the tissues were rapidly homogenized in ice-cold saline (9 times of tissue weight) with a homogenizer. The homogenates were centrifuged at $4500 \mathrm{~g}$ at $4^{\circ} \mathrm{C}$ for $15 \mathrm{~min}$, and the supernatant was collected for determination of acetylcholinesterase (AChE), total antioxidant capacity (T-AOC), SOD, CAT activities, and malondialdehyde (MDA) level. Protein concentrations were determined using a protein assay kit (Bio-Rad Laboratories, Hercules, USA). The total antioxidant capacity, total superoxide dismutase, CAT, AChE, and MDA detection kits (Nanjing Jiancheng Bioengineering Institute, Nanjing, China) were used to determine the T-AOC, SOD, CAT, and AChE activities and MDA level according to the protocols. The absorbance was measured at 405, 520, 532,412 , or $550 \mathrm{~nm}$ wavelengths at room temperature. The activities of T-AOC, SOD, CAT, and AChE were expressed in $\mathrm{U} / \mathrm{mg}$ protein, and the MDA level was shown in $\mathrm{nmol} /$ mg protein, respectively.
2.10. RNA Extraction and Quantitative PCR. Total RNA was isolated from the liver and hippocampus of mice with TRIzol reagent (Invitrogen, Carlsbad, CA). NanoDrop 1000 (Thermo, Wilmington, USA) was used to quantify the amount of total RNA. RNA at the amount of $2.5 \mu \mathrm{g}$ was reverse-transcribed and analyzed by quantitative PCR with SYBR Premix EX Taq ${ }^{\mathrm{TM}}$ (Takara, Dalian, China). All realtime reactions were performed on the ABI7500 Multicolor Real-Time PCR detection system (Thermo, Wilmington, USA). A three-step PCR procedure of $20 \mathrm{~s}$ at $95^{\circ} \mathrm{C}, 20 \mathrm{~s}$ at $55^{\circ} \mathrm{C}$, and $20 \mathrm{~s}$ at $68^{\circ} \mathrm{C}$ was applied for 40 cycles. The primer sequences are shown in Table 1 . All results were normalized to $18 \mathrm{~S}$ RNA levels, and the data were analyzed using the $2^{-\Delta \Delta \mathrm{CT}}$ method.

2.11. Statistical Analyses. The results of the behavior tests, organ index, enzyme activities, MDA level, and related gene expression are expressed as mean \pm SEM. Data were analyzed by one-way analysis of variance (ANOVA) followed by Turkey's test for post hoc analysis. For novel object recognition, statistical evaluation was performed by a paired sample $t$-test. Statistical significance was set at $p<0.05$.

\section{Results}

3.1. Effect of MAT on D-Gal-Induced Cognitive Impairment in the Object Recognition Task. The chemical structure of MAT and experimental protocol in this study are shown in Figure 1. The influence of pretreatment with MAT on Dgal-induced memory impairment was initially investigated in the NOR task. VE was used as a standard positive control. Usually, the mice spent more time on the novel object compared to the familiar one. So, compared with the training session, there was a significant increase in the object recognition index in the test session in the control group $(p<0.05)$. D-gal caused a decrease in the difference between training and test for the object recognition index with the comparison of the control group, whereas pretreatment of VE $(100 \mathrm{mg} / \mathrm{kg})$ and MAT ( 2 and $10 \mathrm{mg} / \mathrm{kg}$, oral) abolished the partial amnesic effect of D-gal (Figure 2(b)) $(p<0.01, p<0.01$, and $p<$ 0.001 ). As observed, long-term treatment with $\mathrm{D}$-gal could induce recognition deficit in the NOR test, and this was improved by treatment with VE or MAT. No significant differences were seen in total time spent on the object in all 


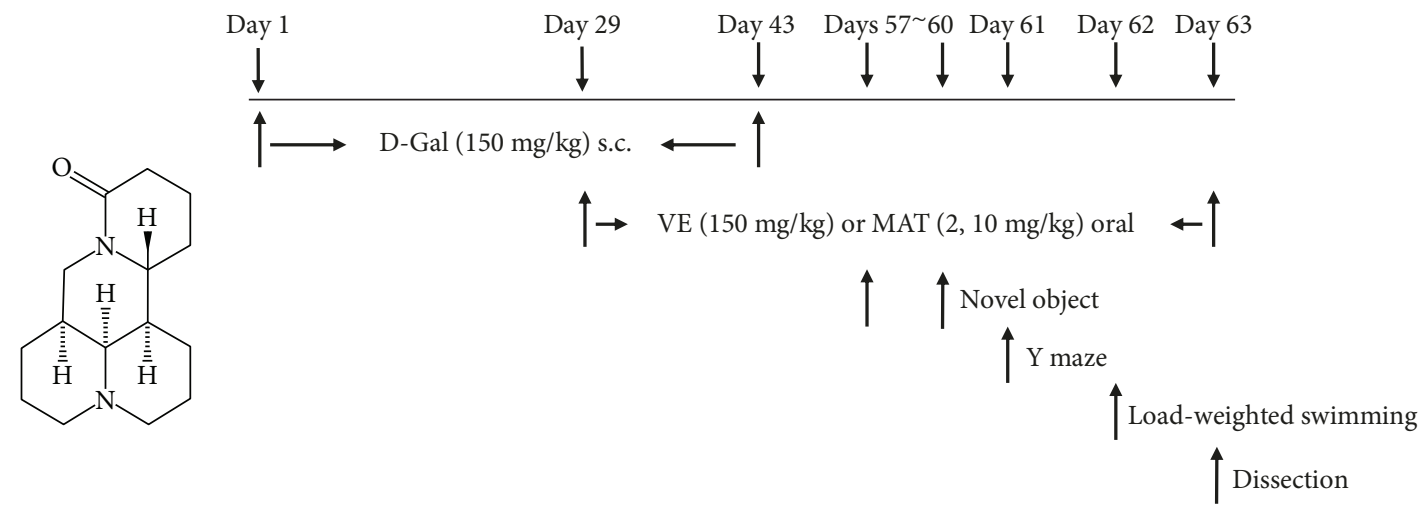

(a)

(b)

Figure 1: (a) The chemical structure of MAT and (b) experimental protocol in this study.

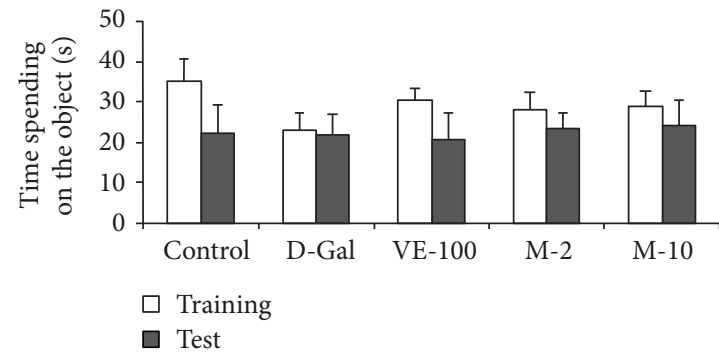

(a)

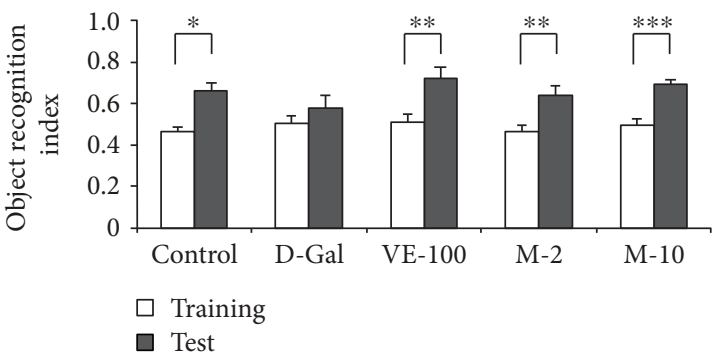

(b)

FIGURE 2: MAT effects on D-gal-induced memory impairment in the novel object recognition test. MAT (2 and $10 \mathrm{mg} / \mathrm{kg}$, oral) was administrated to D-gal-treated mice. D-gal was injected at a dose of $150 \mathrm{mg} / \mathrm{kg}$ for six weeks (s.c.). (a) Time spent on the object in seconds and (b) object recognition index were observed. Results are presented as mean \pm SEM. $n=9,{ }^{*} p<0.05,{ }^{* *} p<0.01$, and ${ }^{* * *} p<0.001$, differences between recognition index in the training and test session. Control received $2 \%$ ethanol in saline + saline, $\mathrm{D}$-gal received $2 \%$ ethanol in saline $+150 \mathrm{mg} / \mathrm{kg} \mathrm{D}$-gal, VE-100 received $100 \mathrm{mg} / \mathrm{kg} \mathrm{VE}+150 \mathrm{mg} / \mathrm{kg} \mathrm{D}$-gal, M-2 received $2 \mathrm{mg} / \mathrm{kg} \mathrm{matrine}+150 \mathrm{mg} / \mathrm{kg} \mathrm{D}$-gal, and $\mathrm{M}-10$ received $10 \mathrm{mg} / \mathrm{kg}$ matrine $+150 \mathrm{mg} / \mathrm{kg} \mathrm{D}$-gal.

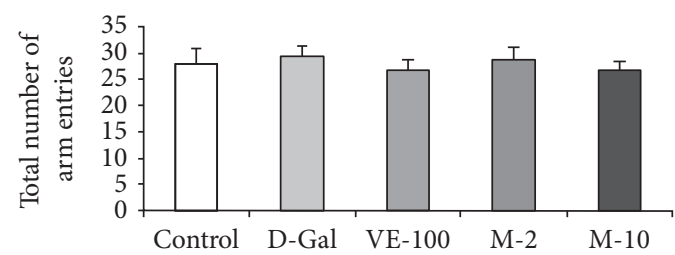

(a)

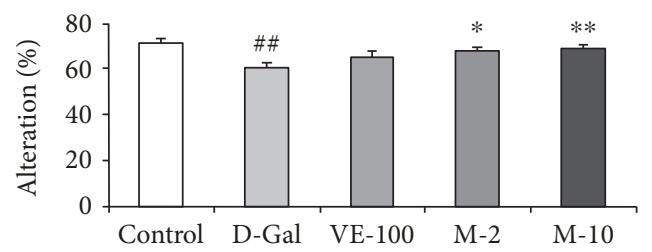

(b)

Figure 3: MAT effects on the Y-maze test. The mice were put into the Y-maze for 8 min one by one. (a) The total number of arm entries and (b) alternations were measured. The data are expressed as mean \pm SEM. $n=9$, \#\# $p<0.01$ vs. vehicle control group and ${ }^{*} p<0.05$ and ${ }^{* *} p<0.01$ vs. D-gal-treated group.

groups (Figure 2(a)). These results suggest that MAT could improve the reference memory impairment caused by D-gal.

\subsection{Effect of MAT on D-Gal-Induced Learning and Memory} Decline in the Y-Maze. The impact of MAT on working memory was investigated in the Y-maze test. D-gal significantly decreased spontaneous alternation relative to the control group (Figure 3(b)) $(p<0.01)$. Moreover, treatment with MAT ( 2 and $10 \mathrm{mg} / \mathrm{kg}$ ) significantly reversed the spontaneous alternation decline caused by D-gal (Figure 3(b)) $(p<0.05, p<0.01)$. However, $\mathrm{VE}$ at $100 \mathrm{mg} / \mathrm{kg}$ did not take effect on alternation decline compared with the D-Gal- treated group (Figure 3(b)). There were no significant differences in arm entries among all the groups (Figure 3(a)). It means that MAT could improve the working memory and short memory but did not affect the locomotor activity of the D-Gal induced model mice.

3.3. Effect of MAT on the Weight-Loaded Forced Swimming Test. The antifatigue impact of MAT was determined in mice by measuring the swimming duration in weightloaded forced swimming. D-gal-treated mice decreased swimming time when compared with the control group $(p<0.05)$ (Figure 4(a)). However, treatment with VE and 


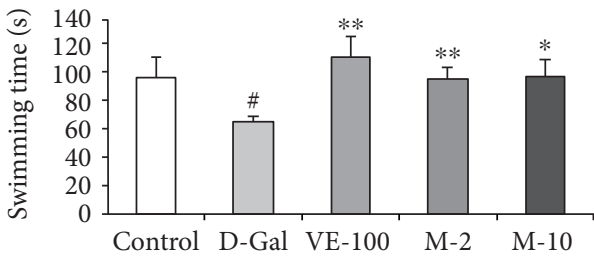

(a)

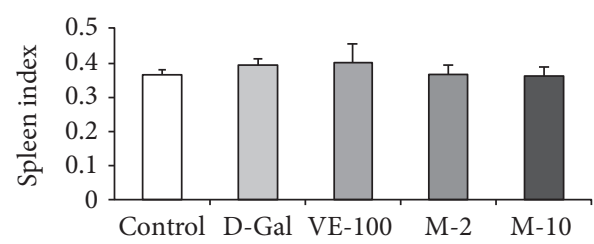

(c)

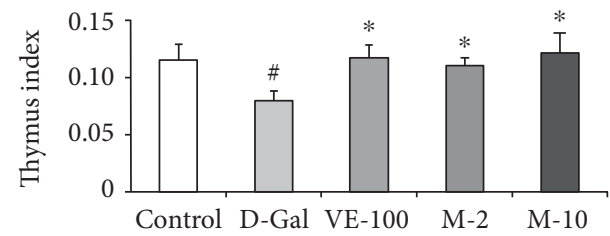

(b)

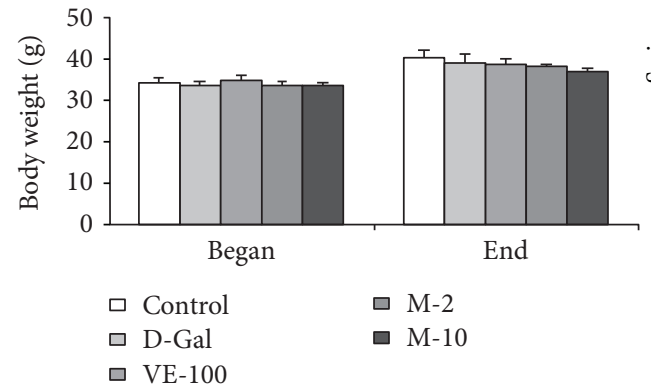

(d)

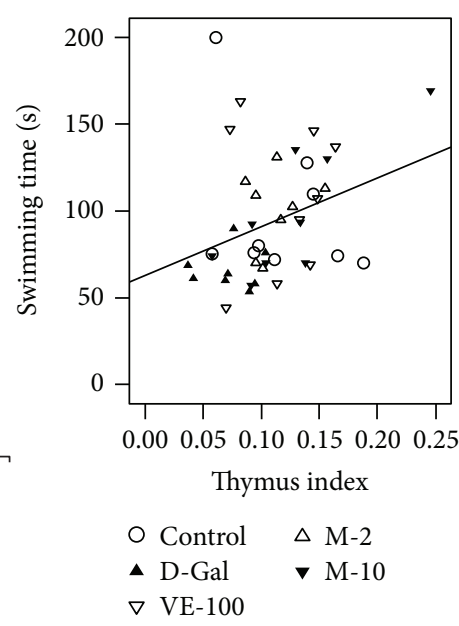

(e)

Figure 4: Effect of MAT on weight-loaded swimming test, thymus and spleen coefficients, body weight in the D-gal-induced aging mice, and Pearson's correlation between the swimming time versus thymus coefficients. (a) The weight-loaded swimming test: mice were loaded aluminum (5\% of their body weight) attached to the tail, and the swimming time was recorded in seconds. (b) The thymus and (c) spleen coefficients: the animals were decapitated after the weight-loaded swimming test, and thymus coefficients were analyzed. (d) The body weight changes between the start of experiment and the end of the experiment. The data are expressed as mean \pm SEM. $n=9$, ${ }^{*} p<0.05$ vs. vehicle control group and ${ }^{*} p<0.05,{ }^{* *} p<0.01$, and ${ }^{* * *} p<0.001$ vs. D-gal-treated group. (e) Pearson's correlation between swimming time versus thymus coefficients was determined. Control group (saline $+2 \%$ ethanol in saline, hollow circle), $\mathrm{D}$-gal group (D-gal $150 \mathrm{mg} /$ $\mathrm{kg}+2 \%$ ethanol in saline, filled triangle), VE-100 (D-gal $150 \mathrm{mg} / \mathrm{kg}+\mathrm{VE} 100 \mathrm{mg} / \mathrm{kg}$, inverted hollow triangle), M-2 (D-gal $150 \mathrm{mg} / \mathrm{kg}+$ matrine $2 \mathrm{mg} / \mathrm{kg}$, hollow triangle), and M-10 (D-gal $150 \mathrm{mg} / \mathrm{kg}$ + matrine $10 \mathrm{mg} / \mathrm{kg}$, inverted filled triangle), $n=45$.

MAT (2 and $10 \mathrm{mg} / \mathrm{kg}$ ) significantly reversed the swimming time decline caused by D-gal (Figure $4(\mathrm{a}))(p<0.01, p<$ 0.01 , and $p<0.05)$. It means that MAT could improve the physical power of aging mice which is induced by D-gal.

\subsection{Effect of MAT on Body Weight and Organ Indexes. In} mammals, retrogression of immune organs with aging results in the decline of the immune organ coefficients, such as thymus coefficient, which is usually used as a hallmark to evaluate the success of the aging animal model. In the present study, 6 weeks of D-gal treatment induced significant decreases in thymus coefficient $(p<0.05)$ (Figure $4(b))$. VE and MAT supplementation dramatically antagonized such changes induced by $\mathrm{D}$-gal treatment $(p<0.05$ for all groups), suggesting the effective immune organ protection of MAT and VE. However, there was no notable difference in body weight and spleen index among groups (Figures 4(c) and $4(\mathrm{~d}))$.

More importantly, when the linear regression was determined, there was a significant positive correlation between the swimming time versus thymus coefficient $(n=45, r=$ $0.323, p<0.05$ ) (Figure 4(e)).

3.5. Effect of MAT on Liver, Spleen, and Brain Histopathological Alterations. The histological features of the liver sections by HE stained are shown in Figure 5(a), $1 \sim 5$. The D-gal-treated group exhibited a dramatic increase in the related nuclear size $(p<0.001)$, and VE and MAT at 2 and $10 \mathrm{mg} / \mathrm{kg}$ significantly reversed such changes $(p<0.01$, $p<0.01$, and $p<0.05)$. D-gal obviously decreased the percentage of the white pulp of the spleen (Figure 5(a), 6, $p<0.001$ ), and VE and MAT markedly increased the percentage of white pulp area decline induced by D-gal (Figure 5(a), $7 \sim 10, p<0.05, p<0.001$, and $p<0.01)$. Changes in histopathology features of the CA3 region of the hippocampus are shown in Figure 5(a), 11 15. It was demonstrated that the structure of the cell was damaged severely, such as cell apoptosis and necrosis in the D-gal treated group. In contrast, MAT-treated mice showed a reduction in damaged cells. A decline in the number of surviving neurons in the CA3 region was observed in the D-gal group compared with the control $(p<0.001)$. Treatment with VE and MAT produced an obvious improvement on such changes $(p<0.001$ for all groups).

3.6. MAT Effect on the SA- $\beta$-Gal Activity of the Liver, Spleen, and Brain. In order to confirm the protection of MAT, we chose the liver, spleen, and brain as the representative organs to detect the most widely recognized aging biomarker, SA- $\beta$ gal activity. $\mathrm{D}$-gal treatment greatly increased the percentage of SA- $\beta$-gal-positive cells in the liver, spleen, and brain (represented by blue staining in the images, Figure 6) compared with the control group $(p<0.001, p<0.01$, and $p<0.001)$. These confirmed the aging changes of the liver, spleen, and brain. Moreover, supplementation with VE and MAT showed effective inhibition of the percentage of SA- $\beta$-galpositive cells in the liver ( $p<0.001$ for all groups), spleen ( $p<0.01$ for all groups), and brain $(p<0.05, p<0.001$, and 


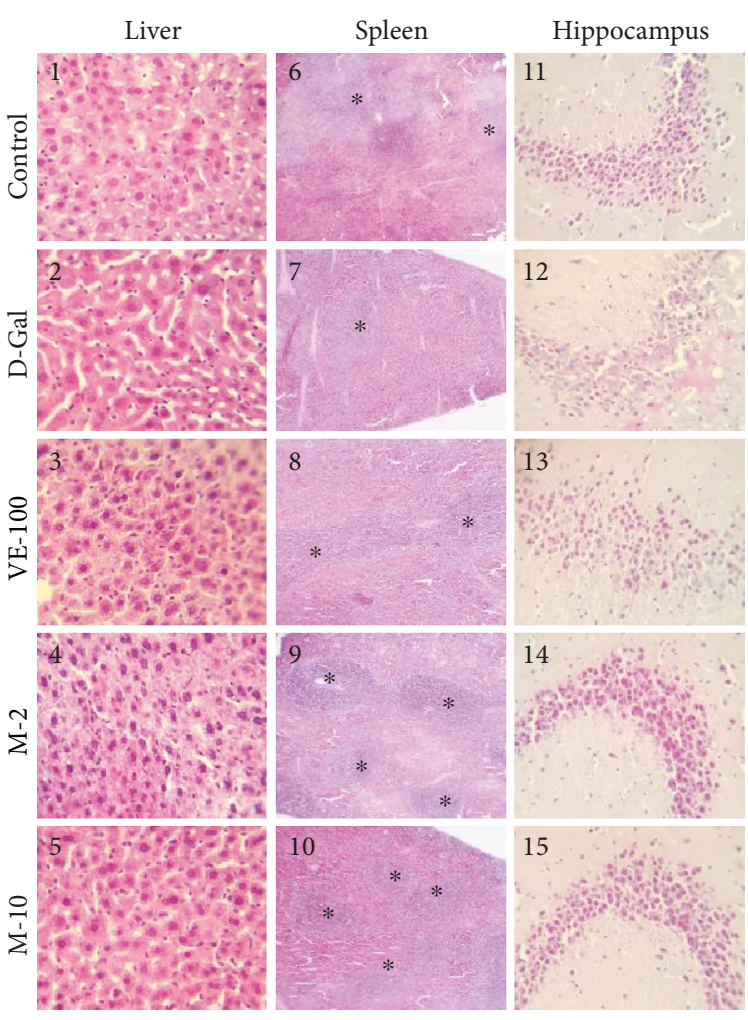

(a)

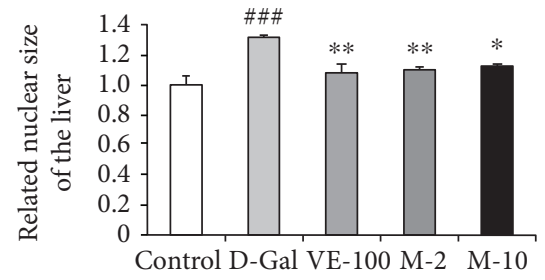

(b)

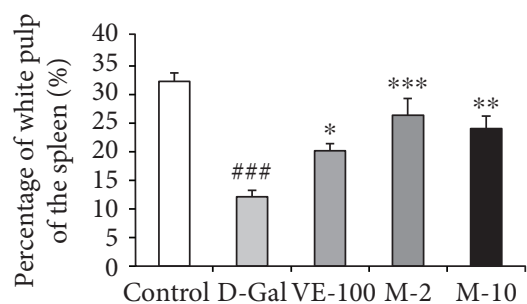

(c)

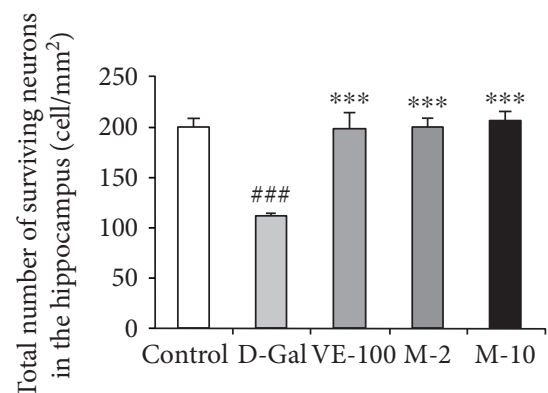

(d)

FIGURE 5: Effect of MAT on liver, spleen, and brain histopathological alterations. (a) The histopathological alterations of the liver, spleen, and brain (HE); the magnification of the liver and brain is 400 times, and that of spleen is 100 times. (b) The related nuclear size of the liver, (c) spleen white pulp proportion, and (d) surviving neurons of CA3 area of the hippocampus. The data are expressed as mean \pm SEM, $n=6$. ${ }^{\# \#} p<0.01$ and ${ }^{\# \# \#} p<0.001$ indicate significant difference compared with the control group; ${ }^{*} p<0.05,{ }^{* *} p<0.01$, and ${ }^{* * *} p<0.001$ indicate significant difference compared with the D-gal-treated control group.

$p<0.001$ ), further confirming the antiaging effect of MAT. These results show that MAT effectively attenuates D-galinduced aging in mice.

More importantly, linear regression was determined which showed that there was a significant positive correlation between the related nuclear size of the liver versus the percentage of SA- $\beta$-gal-positive cell number in the liver (Figure S1A, $r=0.551, p<0.01$ ) and a negative correlation between the percentage of white pulp of the spleen versus the percentage of SA- $\beta$-gal-positive cell number in the spleen (Figure S1B, $r=-0.622, p<0.001$ ) and between the survival cells in the hippocampus versus the percentage of SA- $\beta$-gal-positive cell number in the hippocampus (Figure S1C, $r=-0.622, p<0.001$ ).

3.7. Antioxidative Effect of MAT in Liver, Plasma, and Brain of D-Gal-Induced Aging Mice. Besides that, we also examined the antioxidative effect of MAT on D-gal-induced aging mice. T-AOC was analyzed firstly in the liver, plasma, and brain. It was shown that $\mathrm{D}$-gal significantly decreased $\mathrm{T}$ AOC in all three tissues compared with the control group $(p<0.05, p<0.01$, and $p<0.05)$, and VE and MAT increased T-AOC compared with the D-gal-treated group in the liver $(p<0.05, p<0.05$, and $p<0.01)$, plasma $(p<0.01$, $p<0.05)$, and brain $(p<0.01, p<0.05)$ (Figures $7(\mathrm{a}) 8(\mathrm{a})$, and 9(a)). Then, the T-SOD and CAT activities and MDA level in the liver, plasma, and brain were determined by assay kit. The results showed that relative to the control group, the activity of T-SOD decreased in model mice (Figures 7(b) 8 (b), and 9 (b), $p<0.05$ for all three tissues). Moreover, compared with the model mice, T-SOD increased in the liver $(p<0.05, p<0.05$, and $p<0.001)$, plasma $(p<0.001, p<$ 0.05 , and $p<0.001)$, and brain $(p<0.05, p<0.01$, and $p<$ 0.05 ) of the VE- and MAT-treated group at different concentrations (Figures 7(b)8(b), and 9(b)). Meanwhile, the MDA level increased in the D-gal-treated group in the liver $(p<0.01)$, plasma $(p<0.05)$, and brain $(p<0.001)$, whereas MDA decreased in VE at $100 \mathrm{mg} / \mathrm{kg}$ and MAT at the 2 and $10 \mathrm{mg} / \mathrm{kg}$-treated group in the plasma $(p<0.05$ for all groups) and brain $(p<0.001, p<0.001$, and $p<0.01)$, and MDA decreased in the liver upon treatment with VE at $100 \mathrm{mg} / \mathrm{kg}$ and MAT at $10 \mathrm{mg} / \mathrm{kg}$ ( $p<0.05$ for both groups) (Figures $7(\mathrm{c}) 8(\mathrm{c})$ and $9(\mathrm{c})$ ). The CAT activity reduced in the D-gal-treated group in the liver $(p<0.01)$ and plasma $(p<0.05)$, whereas it was significantly higher than the Dgal-treated group in the liver of the VE- and MAT-treated 


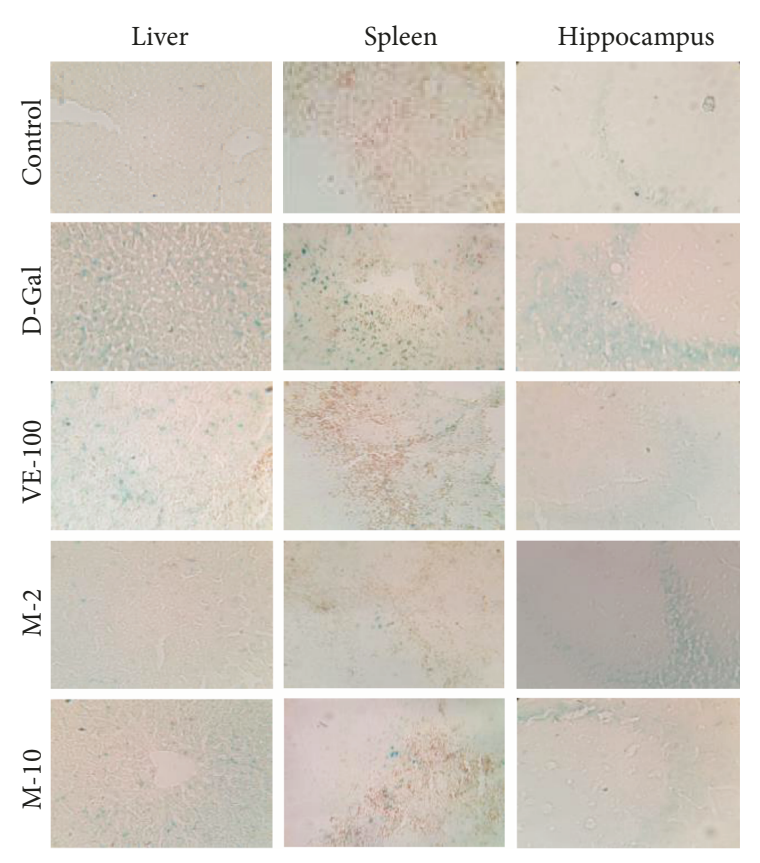

(a)

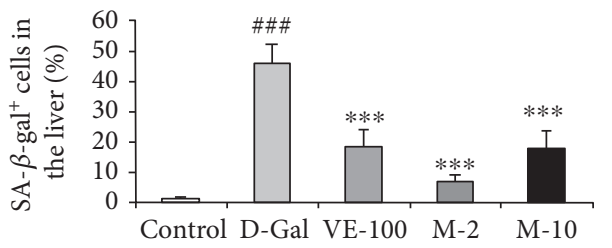

(b)

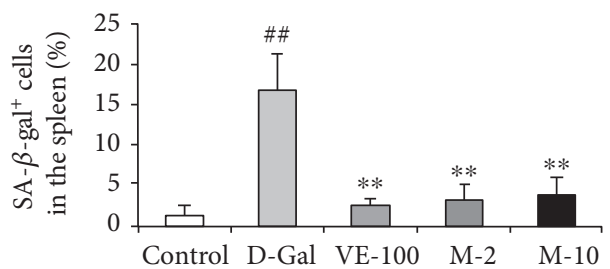

(c)

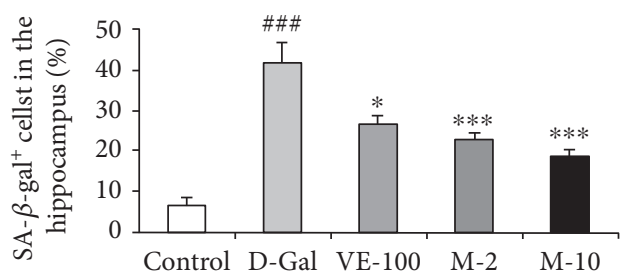

(d)

FIgURE 6: MAT attenuated the increased activity of SA- $\beta$-Gal in liver, spleen, and brain of D-gal-induced aging mice. (a) Representative image of SA- $\beta$-gal staining in each group was captured (magnification 400x). (b-d) Quantification of the percentage of SA- $\beta$-gal-positive cell number in the liver, spleen, and hippocampus. Blue staining means SA- $\beta$-gal-positive cells. The data are expressed as mean \pm SEM, $n=6$. ${ }^{\# \#} p<0.01$ and ${ }^{\# \# \#} p<0.001$ indicate significant difference compared with the control group; ${ }^{*} p<0.05,{ }^{* *} p<0.01$, and ${ }^{* * *} p<0.001$ indicate significant difference compared with the D-gal-treated control group.

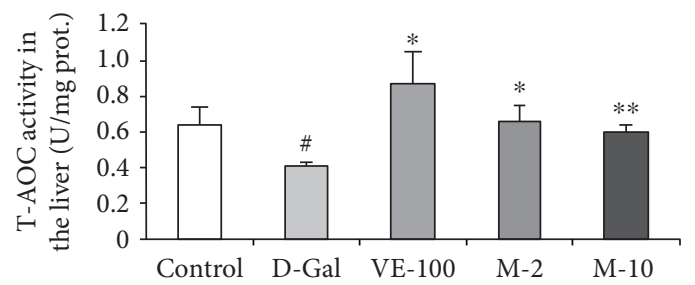

(a)

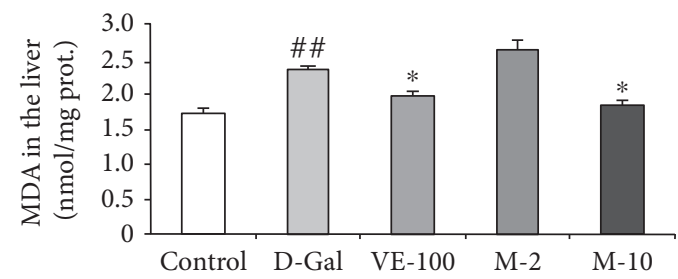

(c)

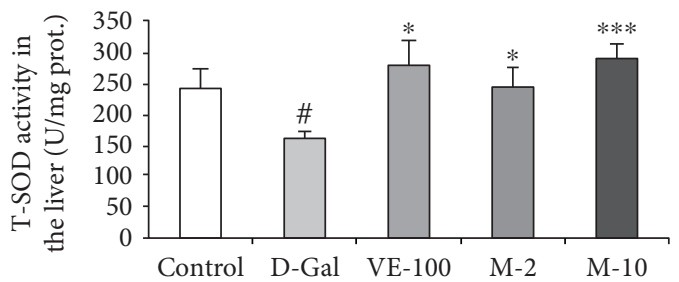

(b)

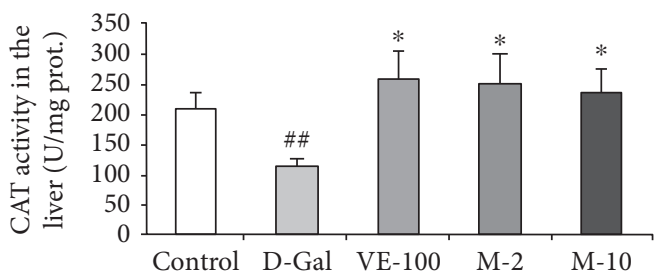

(d)

Figure 7: Effect of MAT on T-AOC, T-SOD, MDA, and CAT activities in the liver of D-gal-induced mice in vivo. (a) Changes in T-AOC, (b) T-SOD activity, (c) MDA level, and (d) CAT activity in the liver. Each value represents the mean \pm SEM of 6 mice. ${ }^{\#} p<0.05$ and ${ }^{\# \#} p<0.01$ indicate significant difference compared with the control group; ${ }^{*} p<0.05,{ }^{* *} p<0.01$, and ${ }^{* * *} p<0.001$ indicate significant difference compared with the D-gal-treated control group.

groups ( $p<0.05$ for all groups) and in the plasma of the MAT-treated groups $(p<0.05, p<0.01)$ (Figures $7(\mathrm{~d})$ and $8(d))$. However, there were no significant differences in CAT activity among all groups in the brain (data not shown). Moreover, we detected the AChE activity in the brain. D-gal obviously increased the AChE level in the brain $(p<0.05)$ relative to the control group, and MAT at both doses inhibited the AChE increase induced by D-gal $(p<0.01, p<$ 0.001 ); however, VE did not affect the AChE activity increase elicited by D-gal treatment (Figure 9(d)). 


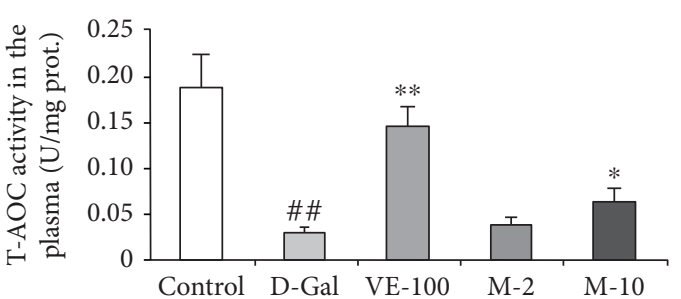

(a)

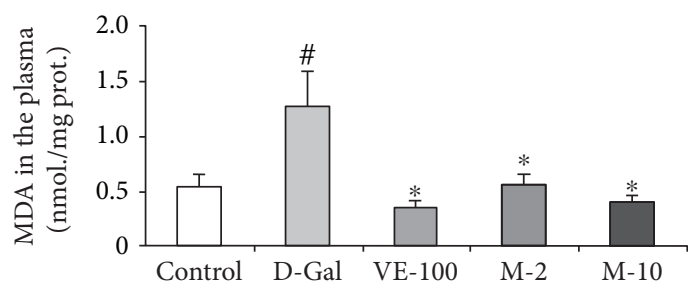

(c)

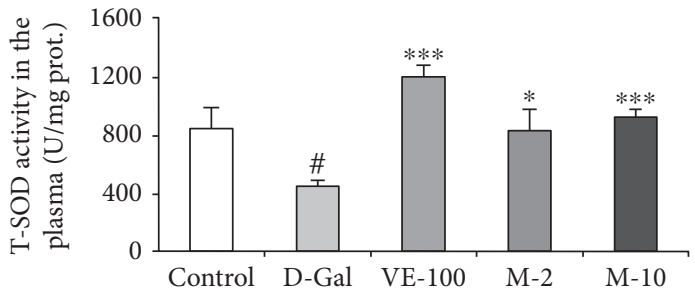

(b)

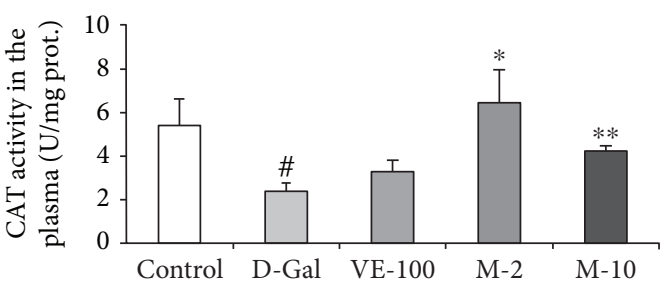

(d)

Figure 8: Effect of MAT on T-AOC, T-SOD, and MDA levels and CAT activity in the plasma of D-gal-induced mice in vivo. (a) Changes in T-AOC, (b) T-SOD activity, (c) MDA level, and (d) CAT activity in the plasma. Each value represents mean \pm SEM of 6 mice. ${ }^{\#} p<0.05$ and ${ }^{\# \#} p<0.01$ indicate significant difference compared with the control group; ${ }^{*} p<0.05,{ }^{* *} p<0.01$, and ${ }^{* * *} p<0.001$ indicate significant difference compared with the D-gal-treated control group.

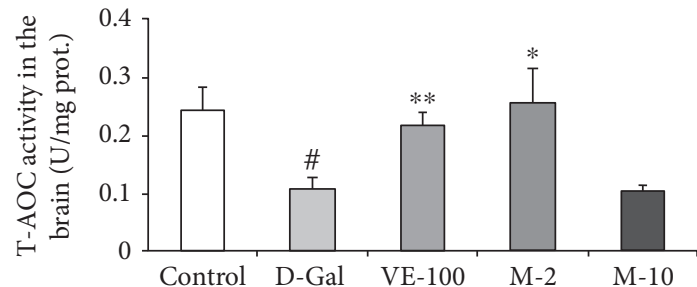

(a)

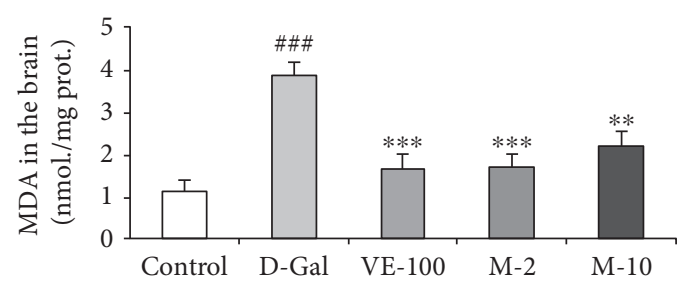

(c)

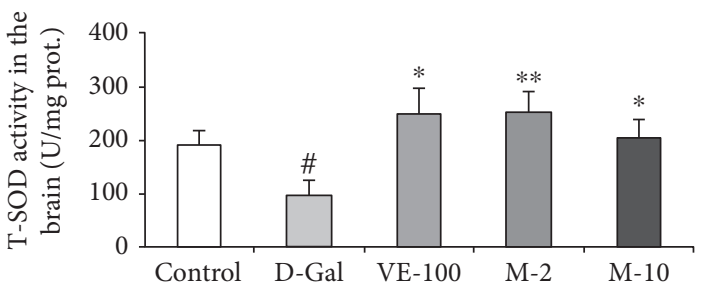

(b)

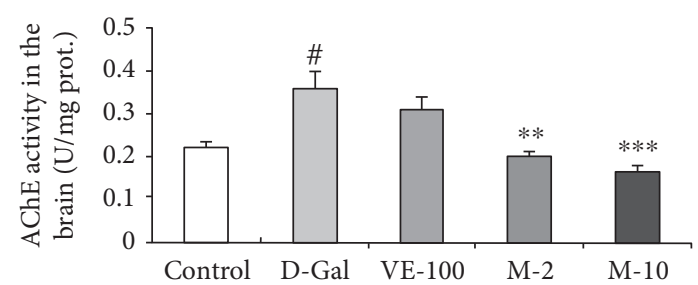

(d)

Figure 9: Effect of MAT on T-AOC, T-SOD, MDA, and AChE activities in the brain. (a) Changes in T-AOC, (b) T-SOD activity, (c) MDA

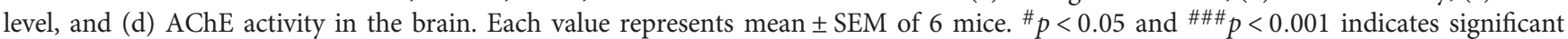
difference compared with the control group; ${ }^{*} p<0.05,{ }^{* *} p<0.01$, and ${ }^{* * *} p<0.001$ indicate significant difference compared with the Dgal-treated control group.

3.8. MAT Effect on p16, p19, p21, IL-1 3 , and IL-6 Gene Expression in the Liver and Hippocampus of D-Gal-Induced Aging Mice. To confirm the effect of MAT on the prevention of cellular senescence, we detected the $p 16, p 19$, and $p 21$ gene expression in the liver and hippocampus. The results showed that the D-gal treated group significantly increased the $p 16, p 19$, and $p 21$ gene expression in the liver $(p<0.01$, $p<0.001$, and $p<0.01)$ and hippocampus $(p<0.01, p<$ 0.05 , and $p<0.01)$ compared with the control group; VE $(100 \mathrm{mg} / \mathrm{kg})$ apparently decreased $p 21$ gene expression of the liver $(p<0.05)$ or MAT $(2,10 \mathrm{mg} / \mathrm{kg})$ and inhibited $p 16, p 19$, and $p 21$ gene expression obviously compared with the D-gal-treated group in the liver $(p<0.05, p<0.05)$, $(p<0.001, p<0.01),(p<0.01, p<0.01) \quad$ (Figure 10(a)). Meanwhile, $p 16, p 19$, and $p 21$ gene expression decreased significantly in the hippocampus after treatment with VE $(100 \mathrm{mg} / \mathrm{kg})$ and MAT $(2,10 \mathrm{mg} / \mathrm{kg})(p<0.01, p<0.01$, and $p<0.01),(p<0.01, p<0.05$, and $p<0.05),(p<0.01, p<$ 0.01 , and $p<0.01$ ) (Figure $10(c))$. Then, we detected the classic components of SASP and the $I L-1 \beta$ and $I L-6$ expression. Related to the control group, the D-gal-treated group significantly increased the $I L-1 \beta$ and $I L-6$ gene expression in the hippocampus $(p<0.001, p<0.01)$; meanwhile, it notably increased $I L-1 \beta$ gene expression in the liver $(p<0.01)$. VE and MAT at doses of 2 and $10 \mathrm{mg} / \mathrm{kg}$ inhibited the $I L-1 \beta$ and IL-6 gene expression compared with the D-gal-treated group 


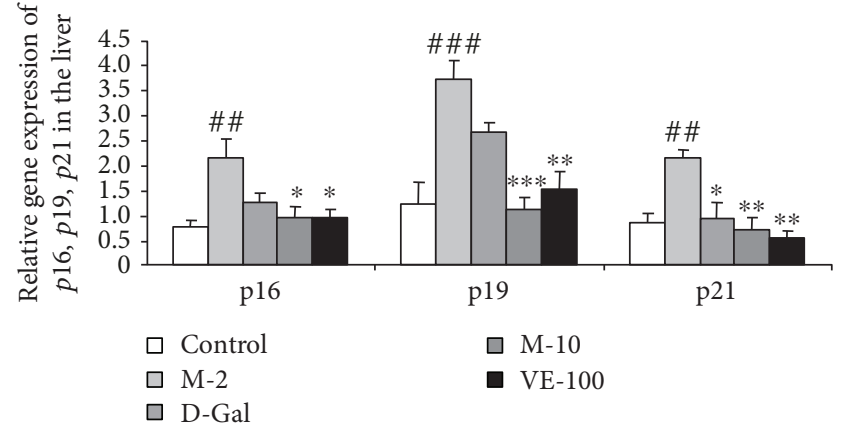

(a)

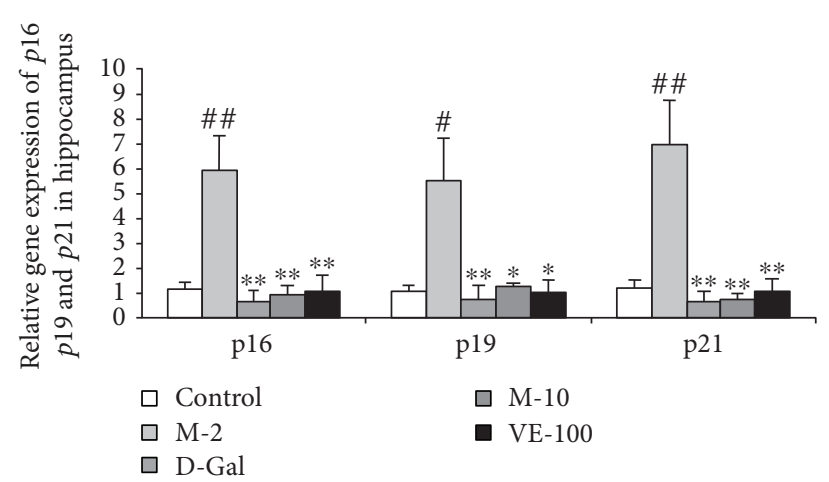

(c)

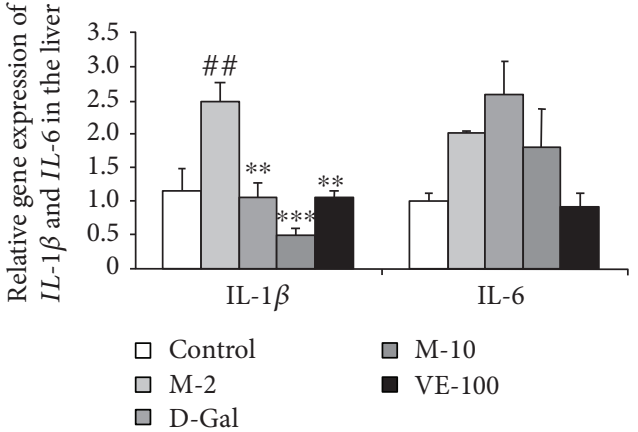

(b)

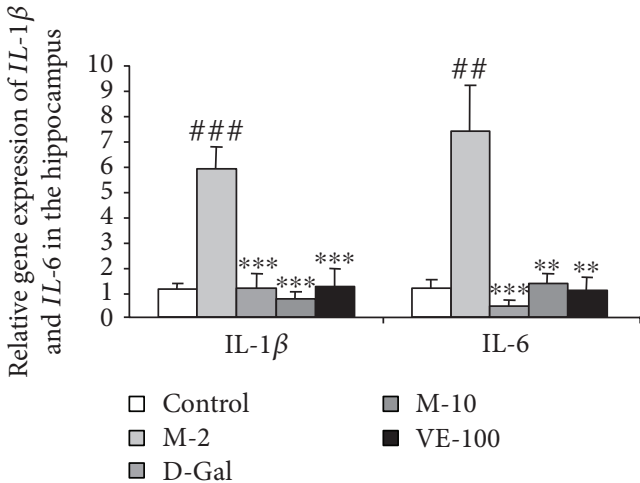

(d)

FIGURE 10: Effect of MAT on $p 16, p 19, p 21, I L-1 \beta$, and $I L-6$ gene expression in the liver $(a, b)$ and hippocampus (c, d) of D-gal-induced aging mice. Each value represents mean \pm SEM of 4 mice. ${ }^{\#} p<0.05$, ${ }^{\# \#} p<0.01$, and ${ }^{\# \# \#} p<0.001$ indicate significant difference compared with the control group; ${ }^{*} p<0.05,{ }^{* *} p<0.01$, and ${ }^{* * *} p<0.001$ indicate significant difference compared with the D-gal-treated control group.

in the hippocampus ( $p<0.001$ for all groups) $(p<0.001$, $p<0.01$, and $p<0.01$ ). Related to the $\mathrm{D}$-gal group, the $I L$ $1 \beta$ gene expression of the liver decreased obviously in the VE and MAT groups $(p<0.01, p<0.001$, and $p<0.01)$ (Figures 10(b) and 10(d)).

\section{Discussion}

Aging is an inevitable process which can affect many functions, such as immune, learning and memory, and exercise endurance. In recent years, the discovery of antiaging active substances has become a hot topic. Chinese Traditional Medicine is a good source for the discovery of active substances. MAT is an alkaloid found in plants of the Sophora genus, which has been used for some treatments, including antidiabetic, antitumor, and isoproterenol-induced heart disease [20-23]. The present study was designed to assess the antiaging activity of MAT. The learning and memory improvement of MAT was investigated using the object recognition and Y-maze tests, and antifatigue effect of MAT was detected by the weight-loaded forced swimming test. We also examined whether the antiaging effect of MAT is involved in inhibition of cellular senescence and oxidative stress by analysis of $\mathrm{HE}$ and SA- $\beta$-gal staining in the liver, spleen, and brain, evaluating the T-AOC, T-SOD, CAT activities and MDA level in the liver, plasma, and brain and detecting related gene expressions of $p 16, p 19, p 21, I L-1 \beta$, and $I L-6$ in the liver and hippocampus.
Previous studies suggested that MAT had neuroprotective effects: MAT alleviated MPTP-induced Parkinson's disease and early brain injury after experimental subarachnoid hemorrhage $[25,29]$. However, the impact of MAT on Dgal-induced learning and memory decline has not been explored. Aging is one of the major factors of brain decline involved in gradual learning and memory loss, cognitive disorders, and dementia, like Alzheimer's disease $[1,2]$. We used the NOR and Y-maze tasks to determine the influence of MAT on cognitive impairment and memory deficits. The results showed that $\mathrm{D}$-gal decreased the object recognition index in the test session, and administration of MAT (2 and $10 \mathrm{mg} / \mathrm{kg}$ ) was effective in preventing the reference memory impairment induced by D-gal (Figure 2(b)). Furthermore, MAT (2 and $10 \mathrm{mg} / \mathrm{kg}$ ) significantly increased the alternation in mice and improved working memory decrease that is caused by D-gal (Figure 3(b)). There were no significant differences among the groups on the exploration time of the object and the number of arm entries; these data agree with the previous research work [30]. Lack of $\mathrm{ACh}$ is one of the pathophysiologies of $\mathrm{AD}$, and $\mathrm{AChE}$ is the primary enzyme that inactivates ACh in the brain [31]. Changes in AChE activity are strongly correlated with learning decline and memory deficits [32]. In this study, D-gal significantly increased the activity of AChE in brain tissue of mice. In contrast, the results showed that MAT markedly reversed the AChE activity. HE and SA- $\beta$-gal staining implied that MAT might improve learning and memory 
ability by maintaining the shape and nuclear integrity of hippocampus CA3 neurons, decreasing the aging cells in the hippocampus in mice. These data are consistent with the results of behavior tests.

People are more prone to fatigue as they get older; fatigue prevalence reached its highest level when the individuals reached age 90 years old for both men and women [3]. The antifatigue effect of MAT was detected by the weightloaded forced swimming test. The results showed that MAT increased the swimming time decline induced by D-gal; these suggested that MAT possesses an antifatigue effect. Fatigue is associated with immune disorder [4], so the organ index of the thymus and spleen was analyzed. The thymus coefficient reduced in the D-gal-treated group, and it was improved by MAT. However, the spleen coefficient did not change among the groups (Figure 4(c)). It did not consist with the previous studies; the D-gal group received daily s.c. injection of D-gal at a dose of $150 \mathrm{mg} / \mathrm{kg}$ for ten weeks [17]. This may because the injection time of $\mathrm{D}$-gal and the mouse strain were different from the report. Next, we detected the histopathological change and aging cells of the spleen. Even there were no significant changes in the spleen index. However, the white pulp proportion reduced in the $\mathrm{D}$-gal group compared with the control, and MAT improved the situation; MAT inhibited the aging cells in the spleen relative to the D-gal group. Also, there was an apparent positive correlation between the swimming time and thymus index. These data mean that MAT produces the antifatigue effect through regulation of immune organs.

The histopathological section showed that MAT protected the aging situation of the liver, spleen, and brain. The related nuclear size of the liver remarkably increased with aging [33], and D-gal apparently decreased spleen white pulp proportion [34] and the surviving neurons of the hippocampus [35] in the previous studies. Also, MAT significantly decreased the related nuclear size of the liver and increased the percentage of the white pulp area and surviving neurons relative to the D-gal group (Figure 5). Recent research work has demonstrated that senescent cells accumulated in various tissues of age and disease [18]. Cellular senescence is associated with age-related phenotypes causally, and decreasing senescent cells can retard tissue dysfunction and extend healthspan [19]. Senescent cell accumulation improved hepatic fat accumulation and liver steatosis, and the reduction in senescent cells by treatment with a combination of dasatinib and quercetin reduced hepatic steatosis globally [36]. The exposure to certain environmental toxins, such as paraquat, improved senescent cell accumulation in the aging brain, which can lead to neurodegeneration, and the elimination of senescent cells protected against paraquat-induced neuropathology [37]. These results suggest that senescent cells are an emerging target for aging-related diseases, and inhibition of senescent cells could delay aging. SA- $\beta$-gal accumulates in senescent cells and is widely used to determine senescence. The results indicate that MAT can protect against senescence of the liver, spleen, and brain. Oxidative stress is one of the major factors to contribute to cellular senescence, and a typical feature of senescence is a shift to a prooxidant redox state. Therefore, numerous researches have shown that treatment with antioxidants could delay the cellular senescence [38]. Moreover, SOD, CAT, and VE are the important members of this antioxidant system [10]. In our studies, MAT could significantly increase T-AOC and TSOD in the liver, plasma, and brain and CAT in the plasma and liver. The influence of MAT on D-gal-induced MDA level increase was observed, and MAT significantly inhibited MDA levels in the plasma, liver, and brain.

p19/p21 and p16 are two major signal pathways during cellular senescence. An increasing expression level of $p 21$ and $p 16$ has been found in aged human and murine fibroblasts and melanocytes [39]. Accumulation of p16 $6^{\text {Ink4a }}$-positive cells during adulthood shorten healthy lifespan and accelerate age-dependent changes in several organs [40]. Moreover, clearance of $\mathrm{p} 16^{\text {Ink4a }}$-positive senescent cells delays aging-associated disorders [19]. The $p 16$ expression could be used as a biomarker of physiologic age [41]. The deletion of $p 21$ improved stem cell function and lifespan of mice with dysfunctional telomeres without accelerating cancer formation [42]. Oxidative stress caused DNA damage and telomere uncapping, which induced $p 19 / p 21$ activation and activated $p 16$ expression through p38-MAPK. $p 16$ and p19/ p21 activation promoted cellular senescence [39]. To confirm the effect of MAT on prevention of cellular senescence, we detected the $p 16, p 19$, and $p 21$ gene expression in the liver and hippocampus. The results showed that D-gal increased $p 16, p 19$, and $p 21$ gene expression in the liver and hippocampus as previously reported $[16,43,44]$. MAT significantly ameliorated such changes. Furthermore, we detected the classic components of SASP, $I L-1 \beta$, and $I L-6$ expression in the hippocampus and liver. The results showed that MAT obviously inhibited the increase in $I L-1 \beta$ and $I L-6$ in the hippocampus and $I L-1 \beta$ expression in the liver that is caused by D-gal. These results are consistent with SA- $\beta$-gal staining. Our results suggest that the antiaging effects of MAT may be due to the inhibition of cellular senescence and oxidative stress.

\section{Conclusion}

In summary, the present research work provided evidence that MAT ameliorated the D-gal-induced cognitive impairment and memory deficits in the NOR and Y-maze tasks in mice, as well as fatigue in the weight-loaded forced swimming test. HE and SA- $\beta$-gal staining showed that MAT could protect liver, spleen, and brain aging. In addition, the potent antiaging effects of MAT may be partly linked to inhibition of cellular senescence and antioxidant activity in the liver, plasma, and brain. These suggest that MAT may be a candidate for the prevention or treatment of aging-relative disorders (Figure S2).

\section{Abbreviations}

AChE: Acetylcholinesterase

CAT: Catalase

D-gal: D-Galactose

HE: Haematoxylin and eosin

IL: Interleukin 


$\begin{array}{ll}\text { MAT: } & \text { Matrine } \\ \text { MDA: } & \text { Malondialdehyde } \\ \text { NOR: } & \text { Novel object recognition } \\ \text { ROS: } & \text { Reactive oxygen species } \\ \text { SASP: } & \text { Senescence-associated secretory phenotype } \\ \text { SA- } \beta \text {-gal: } & \text { Senescence-associated } \beta \text {-galactosidase } \\ \text { T-AOC: } & \text { Total antioxidant capacity } \\ \text { T-SOD: } & \text { Total superoxide dismutase } \\ \text { VE: } & \text { Vitamin E. }\end{array}$

\section{Data Availability}

The data used to support the findings of this study are included within the article and the supplementary information files.

\section{Conflicts of Interest}

The authors declare no competing financial interest.

\section{Acknowledgments}

This work was supported by the grant from Shanxi Agricultural University Science and Technology Innovation Fund (2014YJ04), China.

\section{Supplementary Materials}

Figure S1: Pearson's correlation between histopathological alterations and cellular senescence of the liver, spleen, and hippocampus. Pearson's correlation (A) between the related nuclear size of the liver versus the percentage of SA- $\beta$-gal-positive cell number in the liver, (B) between the percentage of white pulp of the spleen versus the percentage of SA- $\beta$-gal-positive cell number in the spleen, and $(C)$ between the survival cells in the hippocampus versus the percentage of SA- $\beta$-gal-positive cell number in the hippocampus was determined. Control group (saline + $2 \%$ ethanol in saline, hollow circle), D-gal group (D-gal $150 \mathrm{mg} / \mathrm{kg}+2 \%$ ethanol in saline, filled triangle), VE-100 (D-gal $150 \mathrm{mg} / \mathrm{kg}+\mathrm{VE} 100 \mathrm{mg} / \mathrm{kg}$, inverted hollow triangle), M-2 (D-gal $150 \mathrm{mg} / \mathrm{kg}+$ matrine $2 \mathrm{mg} / \mathrm{kg}$, hollow triangle), M-10 (D-gal $150 \mathrm{mg} / \mathrm{kg}+$ matrine $10 \mathrm{mg} / \mathrm{kg}$, inverted filled triangle), $n=30$. Figure S2: table of content. Overload D-gal could lead to oxidative stress, which is one of the major factors to contribute to cellular senescence. Cellular senescence is associated with age-related phenotypes causally, such as learning and memory deficits and exercise endurance decline. Moreover, the potent antiaging effects of MAT may be partly linked to the inhibition of oxidative stress and cellular senescence. (Supplementary Materials)

\section{References}

[1] N. Raz, P. Ghisletta, K. M. Rodrigue, K. M. Kennedy, and U. Lindenberger, "Trajectories of brain aging in middle-aged and older adults: regional and individual differences," NeuroImage, vol. 51, no. 2, pp. 501-511, 2010.
[2] J. M. Morrison and P. R. Hof, "Life and death of neurons in the aging brain," Science, vol. 278, no. 5337, pp. 412-419, 1997.

[3] H. Meng, L. Hale, and F. Friedberg, "Prevalence and predictors of fatigue in middle-aged and older adults: evidence from the health and retirement study," Journal of the American Geriatrics Society, vol. 58, no. 10, pp. 2033-2034, 2010.

[4] K. B. Norheim, G. Jonsson, and R. Omdal, "Biological mechanisms of chronic fatigue," Rheumatology, vol. 50, no. 6, pp. 1009-1018, 2011.

[5] M. Shichiri, N. Harada, N. Ishida et al., "Oxidative stress is involved in fatigue induced by overnight deskwork as assessed by increase in plasma tocopherylhydroqinone and hydroxycholesterol," Biological Psychology, vol. 94, no. 3, pp. 527533, 2013.

[6] K. Shinmura, "Effects of caloric restriction on cardiac oxidative stress and mitochondrial bioenergetics: potential role of cardiac sirtuins," Oxidative Medicine and Cellular Longevity, vol. 2013, Article ID 528935, 11 pages, 2013.

[7] D. Harman, "Aging: a theory based on free radical and radiation chemistry," Journal of Gerontology, vol. 11, no. 3, pp. 298-300, 1956.

[8] R. S. Sohal and R. Weindruch, "Oxidative stress, caloric restriction, and aging," Science, vol. 273, no. 5271, pp. 59-63, 1996.

[9] R. S. Sohal and W. C. Orr, "The redox stress hypothesis of aging," Free Radical Biology and Medicine, vol. 52, no. 3, pp. 539-555, 2012.

[10] M. H. Vendelbo and K. S. Nair, "Mitochondrial longevity pathways," Biochimica et Biophysica Acta (BBA) - Molecular Cell Research, vol. 1813, no. 4, pp. 634-644, 2011.

[11] H. M. Hsieh, W. M. Wu, and M. L. Hu, "Soy isoflavones attenuate oxidative stress and improve parameters related to aging and Alzheimer's disease in C57BL/6J mice treated with Dgalactose," Food and Chemical Toxicology, vol. 47, no. 3, pp. 625-632, 2009.

[12] J. Lu, Y. L. Zheng, D. M. Wu, L. Luo, D. X. Sun, and Q. Shan, "Ursolic acid ameliorates cognition deficits and attenuates oxidative damage in the brain of senescent mice induced by d-galactose," Biochemical Pharmacology, vol. 74, no. 7, pp. 1078-1090, 2007.

[13] D. Wang, M. Liu, J. Cao et al., "Effect of Colla corii asini (E'jiao) on D-galactose induced aging mice," Biological and Pharmaceutical Bulletin, vol. 35, no. 12, pp. 2128-2132, 2012.

[14] Y. Y. Zhou, X. F. Ji, J. P. Fu et al., "Gene transcriptional and metabolic profile changes in mimetic aging mice induced by D-galactose," PLoS One, vol. 10, no. 7, article e0132088, 2015.

[15] F. Ullah, T. Ali, N. Ullah, and M. O. Kim, "Caffeine prevents d-galactose-induced cognitive deficits, oxidative stress, neuroinflammation and neurodegeneration in the adult rat brain," Neurochemistry International, vol. 90, pp. 114-124, 2015.

[16] J. Zhu, X. Mu, J. Zeng et al., "Ginsenoside Rg1 prevents cognitive impairment and hippocampus senescence in a rat model of D-galactose-induced aging," PLoS One, vol. 9, no. 6, article e101291, 2014.

[17] Y. N. Li, Y. Guo, M. M. Xi et al., "Saponins from Aralia taibaiensis attenuate $\mathrm{D}$-galactose-induced aging in rats by activating FOXO3a and Nrf2 pathways," Oxidative Medicine and Cellular Longevity, vol. 2014, Article ID 320513, 13 pages, 2014. 
[18] B. G. Childs, M. Gluscevic, D. J. Baker et al., "Senescent cells: an emerging target for diseases of ageing," Nature Reviews Drug Discovery, vol. 16, no. 10, pp. 718-735, 2017.

[19] D. J. Baker, T. Wijshake, T. Tchkonia et al., "Clearance of p16 ${ }^{\text {Ink4a }}$-positive senescent cells delays ageing-associated disorders," Nature, vol. 479, no. 7372, pp. 232-236, 2011.

[20] H. Li, X. Li, M. Bai, Y. Suo, G. Zhang, and X. Cao, "Matrine inhibited proliferation and increased apoptosis in human breast cancer MCF-7 cells via upregulation of Bax and downregulation of Bcl-2," International Journal of Clinical and Experimental Pathology, vol. 8, no. 11, pp. 14793-14799, 2015.

[21] Z. Liu, Y. Zhang, Z. Tang et al., "Matrine attenuates cardiac fibrosis by affecting ATF6 signaling pathway in diabetic cardiomyopathy," European Journal of Pharmacology, vol. 804, pp. 21-30, 2017.

[22] Y. Zhang, X. Yang, C. Qiu, F. Liu, P. Liu, and Z. Liu, "Matrine suppresses AGE-induced HAEC injury by inhibiting ROSmediated NRLP3 inflammasome activation," European Journal of Pharmacology, vol. 822, pp. 207-211, 2018.

[23] X. Li, X. Wang, Y. Guo et al., "Regulation of endothelial nitric oxide synthase and asymmetric dimethylarginine by matrine attenuates isoproterenol-induced acute myocardial injury in rats," Journal of Pharmacy and Pharmacology, vol. 64, no. 8, pp. 1107-1118, 2012.

[24] P. Zhao, R. Zhou, X. Y. Zhu et al., "Matrine attenuates focal cerebral ischemic injury by improving antioxidant activity and inhibiting apoptosis in mice," International Journal of Molecular Medicine, vol. 36, no. 3, pp. 633-644, 2015.

[25] F. Meng, J. Wang, F. Ding, Y. Xie, Y. Zhang, and J. Zhu, "Neuroprotective effect of matrine on MPTP-induced Parkinson's disease and on Nrf 2 expression," Oncology Letters, vol. 13, no. 1, pp. 296-300, 2017.

[26] P. H. Botton, M. S. Costa, A. P. Ardais et al., "Caffeine prevents disruption of memory consolidation in the inhibitory avoidance and novel object recognition tasks by scopolamine in adult mice," Behavioural Brain Research, vol. 214, no. 2, pp. 254-259, 2010.

[27] M. Sarter, G. Bodewitz, and D. N. Stephens, “Attenuation of scopolamine-induced impairment of spontaneous alternation behaviour by antagonist but not inverse agonist and agonist ?-carbolines," Psychopharmacology, vol. 94, no. 4, pp. 491495, 1988.

[28] Q. Li, Y. Wang, G. Cai et al., “Antifatigue activity of liquid cultured Tricholoma matsutake mycelium partially via regulation of antioxidant pathway in mouse," BioMed Research International, vol. 2015, Article ID 562345, 10 pages, 2015.

[29] X. Liu, X. Zhang, K. Ma et al., "Matrine alleviates early brain injury after experimental subarachnoid hemorrhage in rats: possible involvement of PI3K/Akt-mediated NF- $\kappa \mathrm{B}$ inhibition and Keap 1/Nrf 2-dependent HO-1 induction," Cellular and Molecular Biology, vol. 62, no. 11, pp. 38-44, 2016.

[30] W. Wang, S. Li, H. P. Dong, S. Lv, and Y. Y. Tang, "Differential impairment of spatial and nonspatial cognition in a mouse model of brain aging," Life Sciences, vol. 85, no. 3-4, pp. 127135, 2009.

[31] R. Bartus, R. Dean, B. Beer, and A. Lippa, "The cholinergic hypothesis of geriatric memory dysfunction," Science, vol. 217, no. 4558, pp. 408-414, 1982.

[32] J. A. Araujo, C. M. Studzinski, and N. W. Milgram, "Further evidence for the cholinergic hypothesis of aging and dementia from the canine model of aging," Progress in Neuro-
Psychopharmacology \& Biological Psychiatry, vol. 29, no. 3, pp. 411-422, 2005.

[33] T. Nakajima, T. Nakashima, Y. Okada et al., "Nuclear size measurement is a simple method for the assessment of hepatocellular aging in non-alcoholic fatty liver disease: comparison with telomere-specific quantitative FISH and p 21 immunohistochemistry," Pathology International, vol. 60, no. 3, pp. 175$183,2010$.

[34] J. Zhang, Y. Shao, L. Zhang et al., "Ginsenoside Rg1 relieves the injure of the spleen in aging rats induced by D-galactose," Basic \& Clinical Medicine, vol. 35, no. 10, pp. 1308-1313, 2015.

[35] X. Chen, Y. Li, W. Chen, Z. Nong, J. Huang, and C. Chen, "Protective effect of hyperbaric oxygen on cognitive impairment induced by D-galactose in mice," Neurochemical Research, vol. 41, no. 11, pp. 3032-3041, 2016.

[36] M. Ogrodnik, S. Miwa, T. Tchkonia et al., "Cellular senescence drives age-dependent hepatic steatosis," Nature Communications, vol. 8, 2017.

[37] S. J. Chinta, G. Woods, M. Demaria et al., "Cellular senescence is induced by the environmental neurotoxin paraquat and contributes to neuropathology linked to Parkinson's disease," Cell Reports, vol. 22, no. 4, pp. 930-940, 2018.

[38] L. Á. Maciel-Barón, D. Moreno-Blas, S. L. Morales-Rosales et al., "Cellular senescence, neurological function, and redox state," Antioxidants \& Redox Signaling, vol. 28, no. 18, pp. 1704-1723, 2018.

[39] I. Ben-Porath and R. A. Weinberg, "The signals and pathways activating cellular senescence," The International Journal of Biochemistry \& Cell Biology, vol. 37, no. 5, pp. 961-976, 2005.

[40] D. J. Baker, B. G. Childs, M. Durik et al., "Naturally occurring p16Ink4a-positive cells shorten healthy lifespan," Nature, vol. 530, no. 7589, pp. 184-189, 2016.

[41] B. B. de Jesus and M. A. Blasco, "Assessing cell and organ senescence biomarkers," Circulation Research, vol. 111, no. 1, pp. 97-109, 2012.

[42] A. R. Choudhury, Z. Ju, M. W. Djojosubroto et al., "Cdkn1a deletion improves stem cell function and lifespan of mice with dysfunctional telomeres without accelerating cancer formation," Nature Genetics, vol. 39, no. 1, pp. 99-105, 2007.

[43] T. Shwe, W. Pratchayasakul, N. Chattipakorn, and S. C. Chattipakorn, "Role of D-galactose-induced brain aging and its potential used for therapeutic interventions," Experimental Gerontology, vol. 101, pp. 13-36, 2018.

[44] Y. Z. Zhen, Y. J. Lin, K. J. Li et al., "Effects of rhein lysinate on D-galactose-induced aging mice," Experimental and Therapeutic Medicine, vol. 11, no. 1, pp. 303-308, 2016. 


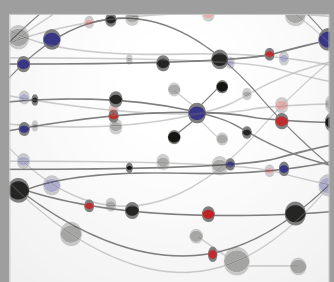

The Scientific World Journal
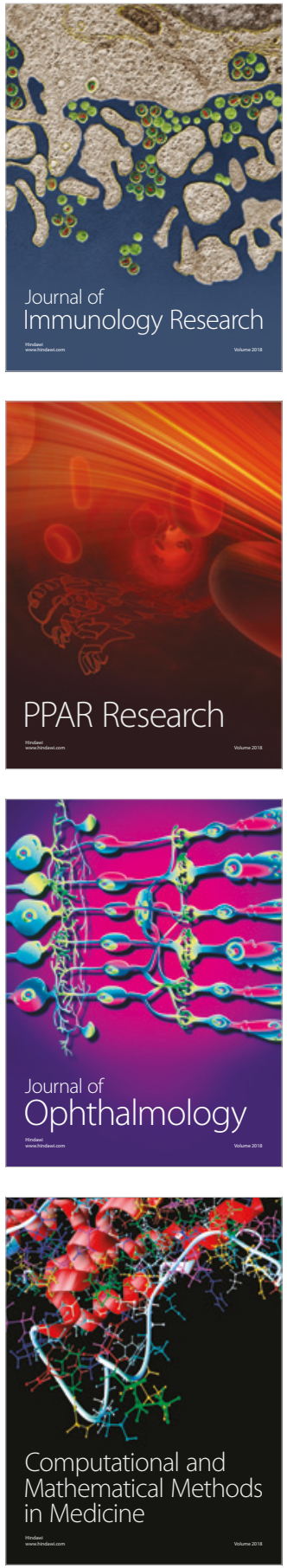

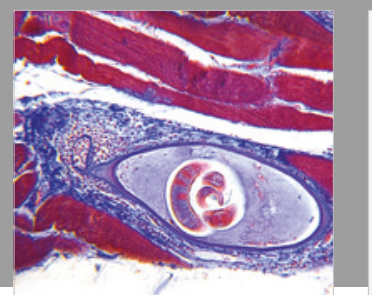

Gastroenterology Research and Practice

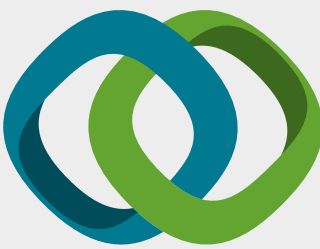

\section{Hindawi}

Submit your manuscripts at

www.hindawi.com
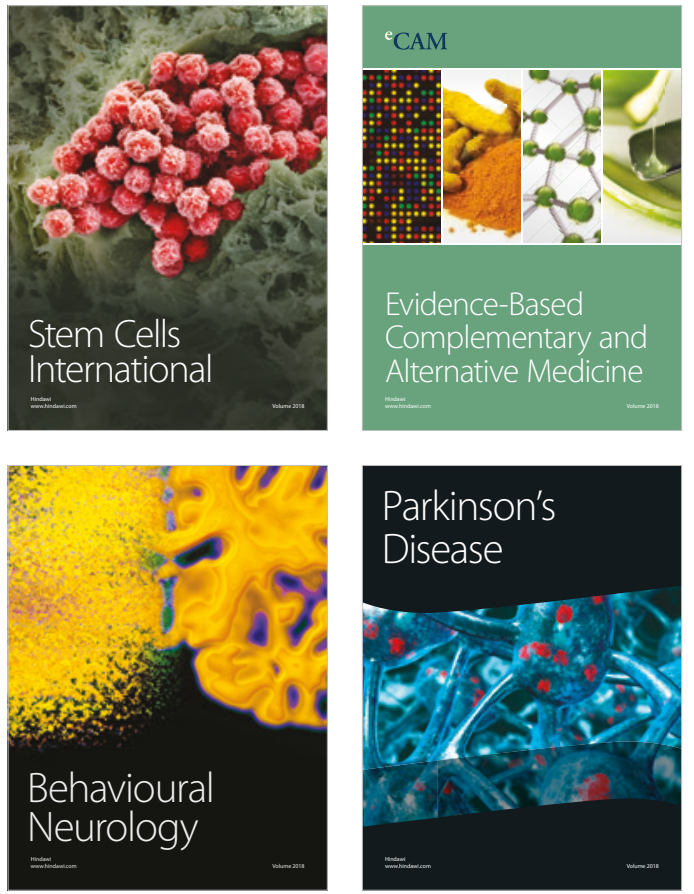

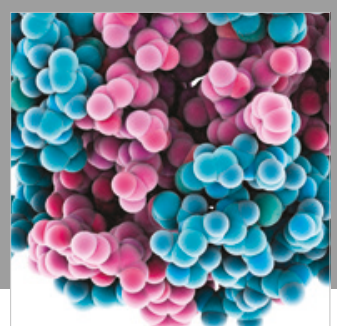

ournal of

Diabetes Research

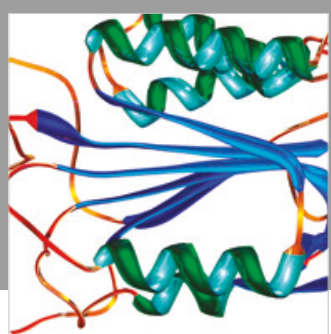

Disease Markers
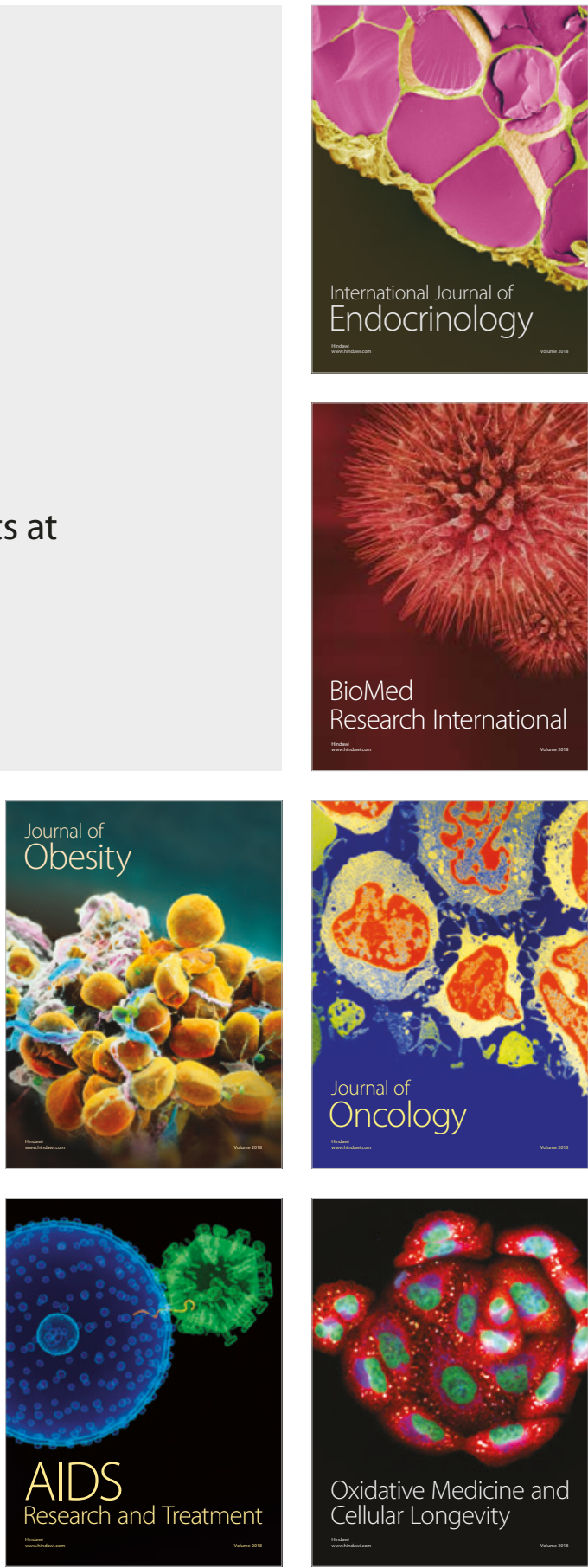